\title{
Comparative Study of LIGAND Docking
}

\author{
M.Naresh Babu \\ Associate Professor \\ Dept. Of CSE \\ Lendi Institute of \\ Engg. \& Tech \\ e-mail:
}

\author{
Patchikolla \\ Satheesh \\ Associate Professor, \\ CSE Department, \\ MVGR College of \\ Engineering, \\ Vizainagaram, AP,
}

\author{
R S Datta Teja \\ Grandhi \\ Research Scholar
}

\author{
Prof. Allam Appa \\ Rao \\ Vice-Chancellor \\ JNT University \\ Kakinada \\ INDIA
}

\begin{abstract}
Anti-apoptotic proteins play an vital role in deactivating the apoptosis process in cancer disease. Apoptosis process can be activated in cancer state by inhibiting anti-apoptotic proteins. Apoptosis occurs via 2 main signalling pathways the Intrinsic and Extrinsic pathways. Extrinsic pathway is regulated by $p 53$ protein, cyt $c$ and apaf- 1 regulates the intrinsic pathway. A class of caspase cascades $(2,3,6,7,8,9)$ helps in induction, transduction, amplification and execution of apoptotic signals in intrinsic and extrinsic signalling pathways.

Comparative docking studies are done on the anti-apototic proteins which disclosed their interaction energies.

Hence forth anti-apoptotic proteins were chosen to perform docking studies which are assumed that the inhibitors/chemical ligands can activate apoptosis process which may precede to inhibit cancer cells uncontrolled proliferation.
\end{abstract}

Keywords: Computer Science, Computer Engineering, Interdisciplinary Research, Applications of Computer Science Techniques for medical diagnosis, Diabetes mellitus, Interdisciplinary Research, Applications of Computer Science Techniques for medical diagnosis, Docking, Rigid Docking, anti apoptotic proteins.

\section{INTRODUCTION}

Apoptosis is the active process of programmed cell death. This mechanism plays an important role in both tissue homeostasis, embryonic development and helps to eliminate the damaged or unneeded cells. Cell undergoing apoptosis process exhibit morphological changes such as cell shrinkage, condensation, fragmentation of the nucleus and bubbling of the plasma membrane. The malfunction of the apoptosis process leads to cancer development and tumour cell.

Apoptosis is mainly regulated by two signalling pathways
1) Intrinsic pathway
2) Extrinsic pathway.

Intrinsic pathway is initiated from within the cell Triggered by protein. This pathway of apoptosis hinges on the balance of activity between pro-and anti-apototic members of the Bcl-2 super family which tend to regulate the permeability of mitochondrial membrane by their activity. Cyt c, apaf-1 and caspase-9 are released from mitochondrial membrane which on assembling to form apoptosome (large multi protein structure). Apoptosome helps in multimerization, allosteric regulation of the catalytic activity of caspase- 9 .

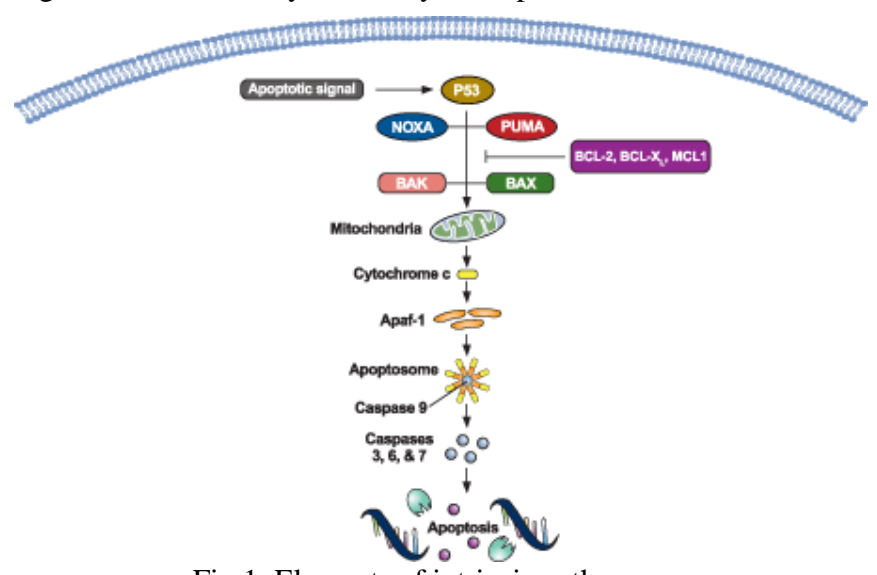

Fig 1: Elements of intrinsic pathway

Extrinsic pathway begins outside the cell through the activation of the pro-apoptotic receptors on the cell surface which are activated by pro-apototic ligands (Fas, fasL, TRAIL). Caspase- 8 plays major rloe in Extrinsic pathway. Formation of the DISC(death induced signalling complex) by association of fas associated death domain(FADD) and caspases 8 or 10 .

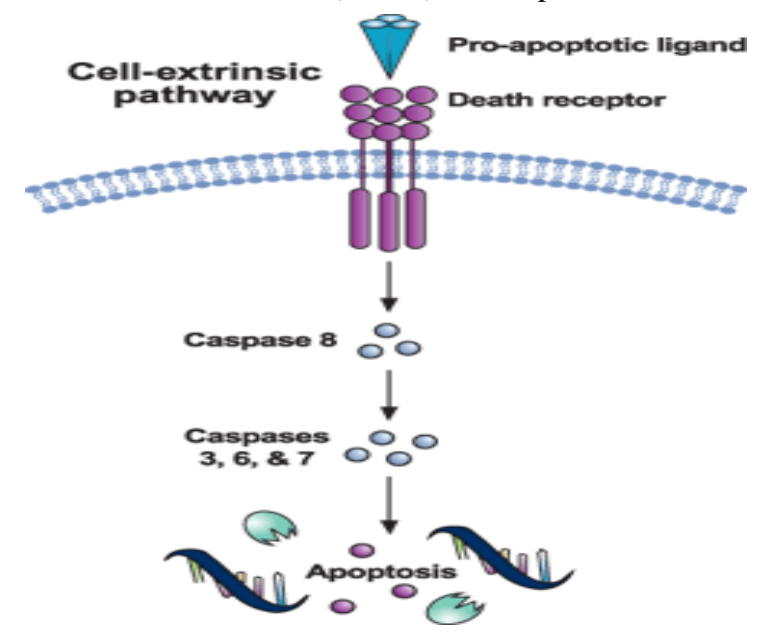

Fig2: Extrinsic pathway of apoptosis. 
Caspases are intracellular cysteine enzymes help in destroying essential cellular proteins leads to controlled cell death. The caspases $(3,6,7,8,9)$ which plays an important role in Induction, Amplification, transduction and execution of apoptotic signalling pathways(Extrinsic, Intrinsic). Caspase cascades are initiated through assembly of multiprotein complexes that trigger activation of the initiator caspases, which are then released and able to activate the downstream effector caspases.

\section{Targeting apoptosis intracellularly}

Therapeutic strategies are also being developed that target apoptosis through the intrinsic pathway. Small-molecule-based antagonists of $\mathrm{Bcl}-2$ family proteins or the IAPs promote apoptosis intracellularly. Inhibition of Bcl-2 family proteins and the IAP family may restore the ability of the intrinsic apoptotic pathway to respond to apoptotic stimuli. There is a smallmolecule inhibitor targeted to anti-apoptotic Bcl-2 family proteins while SMAC/DIABLO mimetics block IAPs and may sensitize cancer cells to apoptosis.

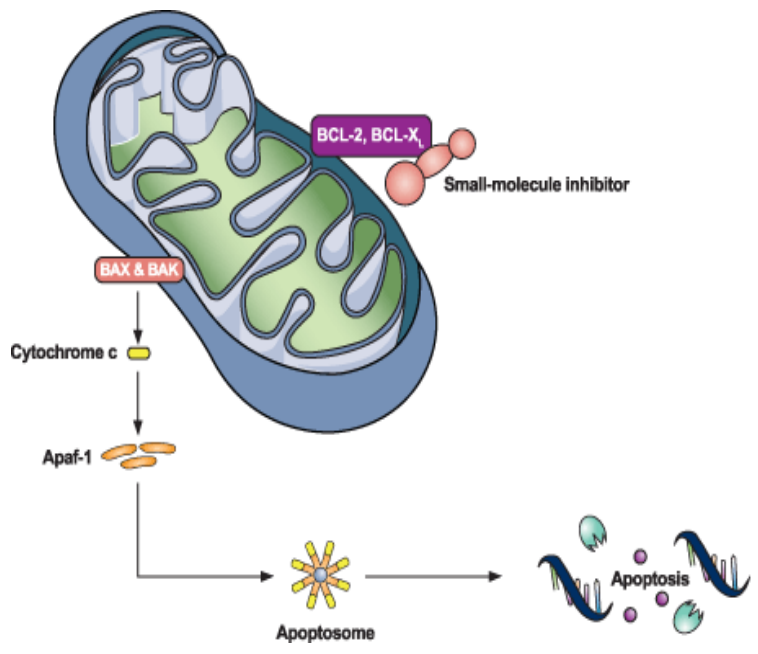

Fig3: Small-molecule inhibitors target the intrinsic apoptotic pathway.

\section{DOCKING:}

Docking is finding the binding geometry of two interacting molecules with known structures. In the field of molecular modeling, docking is a method which predicts the preferred orientation of one molecule to a second when bound to each other to form a stable complex.

\section{Two types of docking:}

\section{RESULTS:}

Rigid docking: In this both the receptor and ligand are kept rigid. Degrees of freedom:

$6(3$ position +3 orientation $)$

Flexible docking: flexibility is allowed for the receptor, or the ligand, or both.

Degrees of freedom: $6+$ Nfree ( 3 position +3 orientation $+\mathrm{Nfree}$ bond) $\mathrm{s}$

\section{MATERIALS AND METHODS}

PDB: The Protein Data Bank (PDB) is a repository for the 3-D structural data of large biological molecules, such as proteins and nucleic acids. The data, typically obtained by X-ray crystallography or NMR spectroscopy. This databank forms key resource in areas of structural biology.

\section{DRUG BANK:}

The DrugBank database is a unique bioinformatics and cheminformatics resource that combines detailed drug (i.e. chemical, pharmacological and pharmaceutical) data with comprehensive drug target (i.e. sequence, structure, and pathway) information. The database contains nearly 4800 drug entries including >1,350 FDA-approved small molecule drugs, 123 FDA-approved biotech (protein/peptide) drugs, 71 nutraceuticals and $>3,243$ experimental drugs.

\section{MOLEGRO VIRTUAL DOCKER:}

Molegro Virtual Docker is an integrated platform for predicting protein - ligand interactions. It handles all aspects of the process, from preparing the molecules to determining the potential binding site of the target protein and predicting the binding mode of the ligand.

Steps in methodology are

1) Importing an protein file and ligand file.

2) Protein preparation and detecting cavities of protein molecules.

3) Executing a docking set up through docking wizard panel.

4) Poses of protein-ligand complex is obtained after docking process with their specific mol dock and Re rank scores displayed in output file.

Table1

\begin{tabular}{|c|c|c|c|}
\hline \multirow{3}{*}{ Protein } & Ligand & Moldock & Rerank score \\
\hline \multirow{3}{*}{ Bcl-2 } & Cpm-1285 & -123.16 & -96.7891 \\
\cline { 2 - 4 } & Bh31-1 & -104.08 & -78.3841 \\
\cline { 2 - 4 } & Terphenyl & -90.54 & -78.8778 \\
\cline { 2 - 4 } & & & -61.92 \\
\hline
\end{tabular}




\begin{tabular}{|c|c|c|c|}
\hline \multirow{7}{*}{ Survivin } & Folic acid & -142.97 & -121.98 \\
\hline & Fusidic acid & -150.17 & -101.266 \\
\hline & 1- aspartic acid & -61.38 & -52.92 \\
\hline & 1-fusidic acid & -69.66 & -62.99 \\
\hline & Leucovorin & -139.83 & -118.03 \\
\hline & Vit-c(ascorbic acid ) & -63.63 & -60.83 \\
\hline & Salicylic acid & -50.95 & -51.20 \\
\hline \multirow{3}{*}{ Clusterin } & $\begin{array}{c}\text { Alpha - methyl-n-acetyl-d- } \\
\text { glucosamine }\end{array}$ & -65.20 & -57.14 \\
\hline & di(n-acetyl-d-glucosamine) & -81.81 & -65.41 \\
\hline & n-acetyl-d-glucosamine & -64.58 & -54.40 \\
\hline \multirow{10}{*}{ Myxoma } & Selenomethionine & -55.81 & -51.78 \\
\hline & Choline & -36.51 & -32.28 \\
\hline & Divalproex & -19.22 & -18.56 \\
\hline & Glycodiazine & -80.71 & -70.34 \\
\hline & Nitroprusside & $-74 . .88$ & -65.76 \\
\hline & Oxybuprocaine & -101.76 & -82.69 \\
\hline & Perchlorate ion & -39.07 & -33.94 \\
\hline & Polysterene sulfate & -26.25 & -22.05 \\
\hline & Sodium lauryl sulphate & -78.84 & -70.13 \\
\hline & Valproic acid & -52.90 & -47.37 \\
\hline
\end{tabular}

SCREEN SHOTS OF HIGH SCORED PROTEIN LIGAND DOCKED POSES:

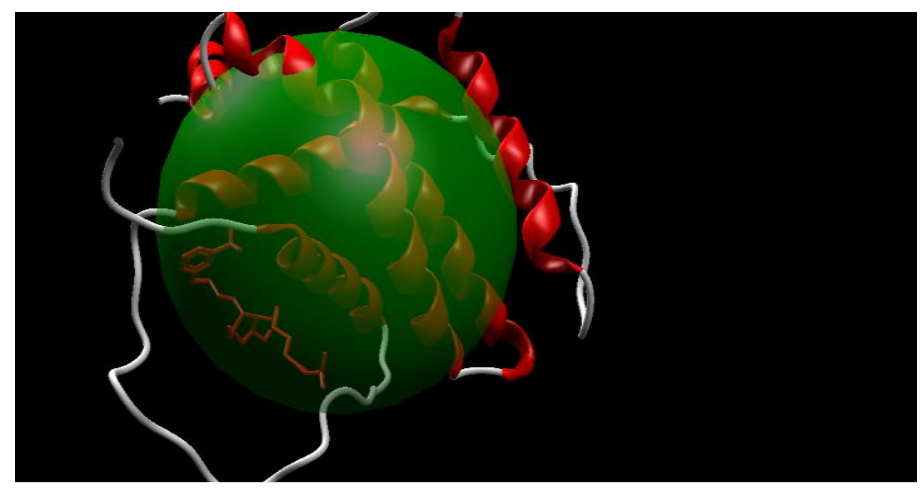

Fig 4: Docked pose of cpm-1285 with bcl-2

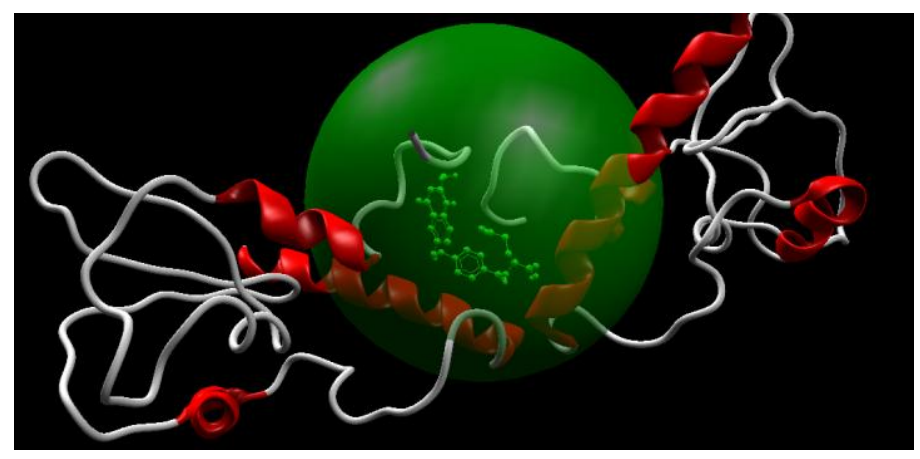

Fig 5: Docked pose of folic acid with survivin. 


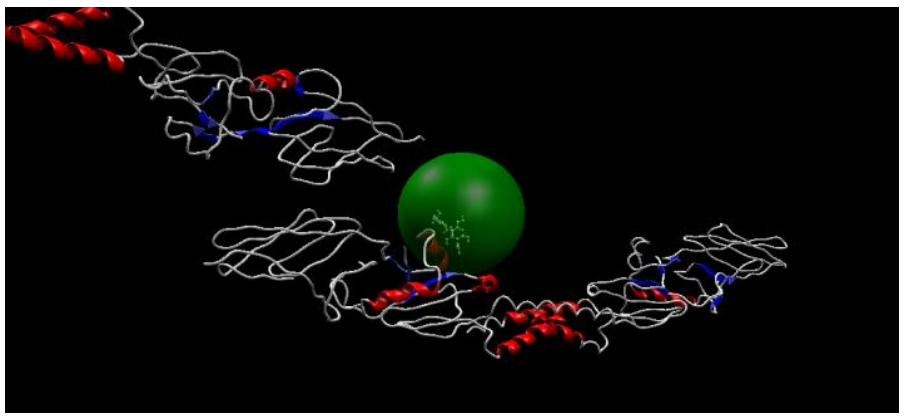

Fig 6: Docked pose of di(n-acetyl glucosamine) with clusterin.

\section{DISCUSSION:}

1) Anti-apoptotic proteins selected for docking studies, which play an vital role in deactivating the apoptosis process in cancer disease.

2) Programmed cell death (Apoptosis) process can be activated in cancer state by inhibiting the antiapoptotic proteins.

3) Thefamily of "Inhibitors of apoptosis" which inhibit the apoptosis process are

\section{1)BCL-2 \\ 2)SURVIVIN \\ 3)MYXOMA}

4)CLUSTERIN

4) comparitive docking studeis are done on anti-apoptotic proteins and their ligands which disclosed their interaction energies.

5) Docking scores obtained with anti-apoptotic proteins with selective ligands revealed the effective drug moleculeswhich can inhibit the respective antiapoptotic proteins.

\section{CONCLUSION:}

6) The best scoring ligands were identified by best docked scores obtained in comparitive docking studies of ligands with anti-apoptotic proteins.

7) Identified ligands can be explored further to generate more effective and potential drug molecules through ligand based drug designing approaches.

8) These docking studies also provide indepth understanding of the interaction at their binding sites of ligand groups and receptor sites.

9) These studies also provide a platformto ease the docking studies on other anti-apoptotic proteins which play an contributing role in area of cancer.

10) Hence forth the anti-apototic proteins were chosen to perform docking studies which are assumed that the inhibitors/chemical ligands can activate the apoptosis process which inturn preceede to inhibit the cancer cell proliferation.

\section{REFERENCES:}

1. Altschul, S. F., Madden, T. L., Schaffer, A. A., Zhang, Z., Miller, W., Lipman, D. J. (1997) Gapped BLAST and PSI-BLAST: a new generation of protein database search programs. Nucleic Acids Res. 25, 3389-3402
2. Dean Y. Maeda,a, Sumit S. Mahajan,b William M. Atkinsb and John A. Zebala (April 2006) Bivalent inhibitors of glutathione S-transferase: The effect of spacer length on isozyme selectivity, J Bioorganic \& Medicinal Chemistry, 3780-3783

3. Gehlhaar, D. K.; Verkhivker, G.; Rejto, P. A.; Fogel, D. B.; Fogel, L. J.; Freer, S. T. (1995) Docking Conformationally Flexible Small Molecules Into a Protein Binding Site Through Evolutionary Programming. Proceedings of the Fourth International Conference on Evolutionary Programming, No $123-124$

4. Hayes JD, Pulford DJ (1995) The glutathione S-transferase supergene family: regulation of GST and the contribution of the isoenzymes to cancer chemoprotection and drug resistance 30(6):445-600, Crit Rev Biochem Mol Biol. 24-23

5. Introduction to Bioinformatics. By, Teresa K. Attwood, David Parry-Smith. Edition, 1st edition, May 2001. Format, Paperback textbook, 240pp ...

6. Jiao L, Bondy ML, Hassan MM, Chang DZ, Abbruzzese $\underline{\text { JL}}$ Evans DB, Smolensky MH, Li D (2007): Glutathione Stransferase gene polymorphisms and risk and survival of pancreatic cancer, Cancer. No: 8-9

7. Kidd LC, Woodson K, Taylor PR, Albanes D, Virtamo

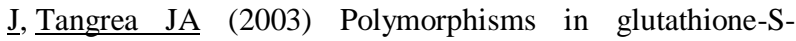
transferase genes (GST-M1, GST-T1 and GST-P1) and susceptibility to prostate cancer among male smokers of the ATBC cancer prevention study Eur J Cancer Prev.,21-22

8. Laskowski, R. A., MacArthur, M. W., Moss, D. S. and Thronton, J. M. (1993) PROCHECK: a program to check the stereochemical quality of protein structures. J. Appl. Cryst. 26, 283-291

9. Ramachandran, G. N., Sasisekharan, V. (1968) Conformation of polypeptides and proteins. Adv. Protein Chem. 23, 283-438.

10. Sali, A. and Blundell, T. L. (1995) Comparative protein modelling by satisfaction of spatial restraints. J. Mol. Biol. 234, 779-815.

11. Sheehan D, Meade G, Foley VM, Dowd CA(2001) Structure, function and evolution of glutathione transferases: implications for classification of non-mammalian members of an ancient enzyme superfamily. Biochem J. Nov 15;

12. FOR BOOK REFERNCE

DataMining - Concepts and Techniques - JIAWEL HAN $\&$ MICHELINE KAMBER Harcourt India. 